\title{
Rupture process of the 2011 Tohoku earthquake from the joint inversion of teleseismic and GPS data*
}

\author{
Yong Zhang Lisheng Xu and Yun-tai Chen" \\ Institute of Geophysics, China Earthquake Administration, Beijing 100081, China
}

\begin{abstract}
Teleseismic and GPS data were jointly inverted for the rupture process of the 2011 Tohoku earthquake. The inversion results show that it is a bilateral rupture event with an average rupture velocity less than $2.0 \mathrm{~km} / \mathrm{s}$ along the fault strike direction. The source rupture process consists of three sub-events, the first occurred near the hypocenter and the rest two ruptured along the up-dip direction and broke the sea bed, causing a maximum slip of about $30 \mathrm{~m}$. The large-scale sea bed breakage may account for the tremendous tsunami disaster which resulted in most of the death and missing in this mega earthquake.
\end{abstract}

Key words: 2011 Tohoku earthquake; rupture process; joint inversion; teleseismic data; GPS data CLC number: PP $315.3^{+} 3$ Document code: A

\section{Introduction}

An earthquake occurred off the Pacific coast of Tohoku, Japan, at 05:46 on 11 March 2011 (UTC) (hereafter referred to Tohoku earthquake). This mega earthquake and its generated tsunami caused about 19009 death and missing. From the location result of USGS/NEIC, the hypocenter of this earthquake is located at $\left(38.322^{\circ} \mathrm{N}, 142.369^{\circ} \mathrm{E}\right)$ with a focal depth of $32 \mathrm{~km}$, which is well consistent with the fault tectonic near the Japan Trench at the plate boundary between Pacific and Okhotsk plates. The earthquake should be the result of the northwestward movement (about 80 $\mathrm{mm} / \mathrm{a}$ ) of the Pacific plate toward and beneath Japan (Seno et al., 1996; Heki et al., 1997) (Figure 1). However, it was unexpected that large earthquakes with magnitude around 9.0 would occur in the epicentral area near the Japan Trench. As the largest earthquake had been recorded in the northwest of the Pacific plate, it is no doubt that the 2011 Tohoku earthquake and its corresponding research will renew our understanding to the seismogenic structure in the area.

\footnotetext{
* Received 19 December 2011; accepted in revised form 23 March 2012; published 10 April 2012.

† Corresponding author. e-mail: chenyt@cea-igp.ac.cn

(C) The Seismological Society of China, Institute of Geophysics, China Earthquake Administration, and Springer-Verlag Berlin Heidelberg 2012
}

There have been many primary results of the focal mechanism and rupture process of this earthquake using teleseismic waves (Zhang et al., 2011; Yagi, 2011; Shao et al., 2011; Wei et al., 2011; Hayes, 2011). These results are quite diverse both in fault slip distribution and in source time function, implicating that some complex rupture behaviors occurred during the source rupture process are hardly to be determined reliably with only one kind of data. In this study, we perform a joint inversion for this mega earthquake by using teleseismic and GPS data, with aims to clarify the source complexity and the disaster mechanism.

\section{Teleseismic and GPS data}

Vertical components of teleseismic $\mathrm{P}$ waves at 32 seismic stations with epicentral distance of $40^{\circ}-90^{\circ}$ are downloaded from the IRIS data center and used in the inversion (Figure 2). After a correction of the instrument response, the waveforms were filtered with a band pass of $0.004-0.1 \mathrm{~Hz}$. The corresponding Green's functions were calculated with reflectivity method (Kennett, 1983) based on the IASPEI model (Kennett and Engdahl, 1991).

The co-seismic GPS data is provided by the ARIA team at JPL and Caltech (version 0.3), with the origin data from GSI of Japan. In this study we only chose the data recorded by the GPS stations within the area 


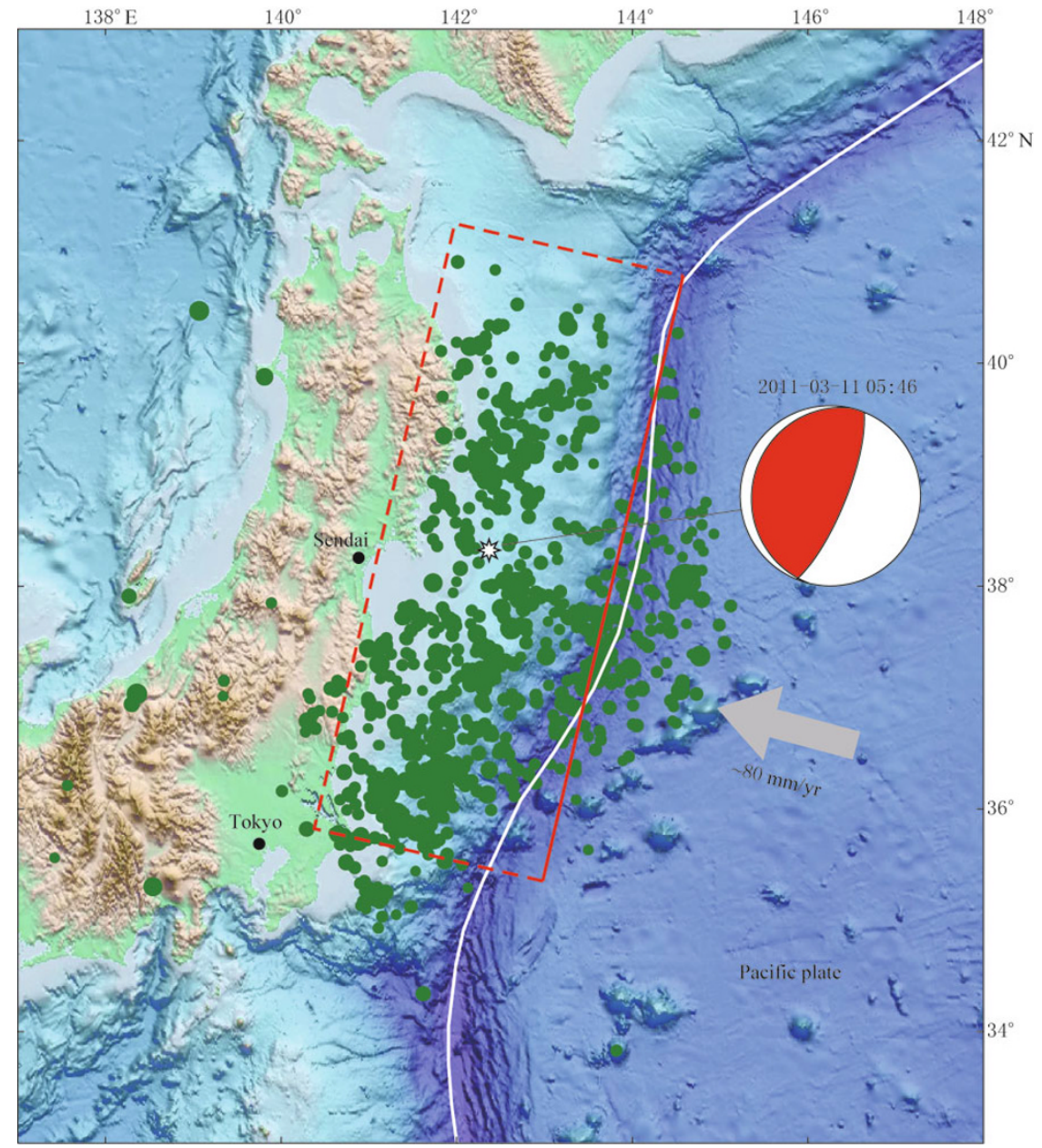

Figure 1 Epicentral area of the 2011 Tohoku earthquake. White aniseed star is the epicentral location; red rectangular denotes the surface projection of the causative fault (full line represents the intersection of the fault and the sea bed); cyan circles are the aftershocks occurred between 11 March 2011 and 29 March 2011 (from USGS); the red beach ball denotes the best double couple (strike $193^{\circ} /$ dip $14^{\circ} /$ rake $81^{\circ}$ ) of USGS WPhase moment tensor solution.

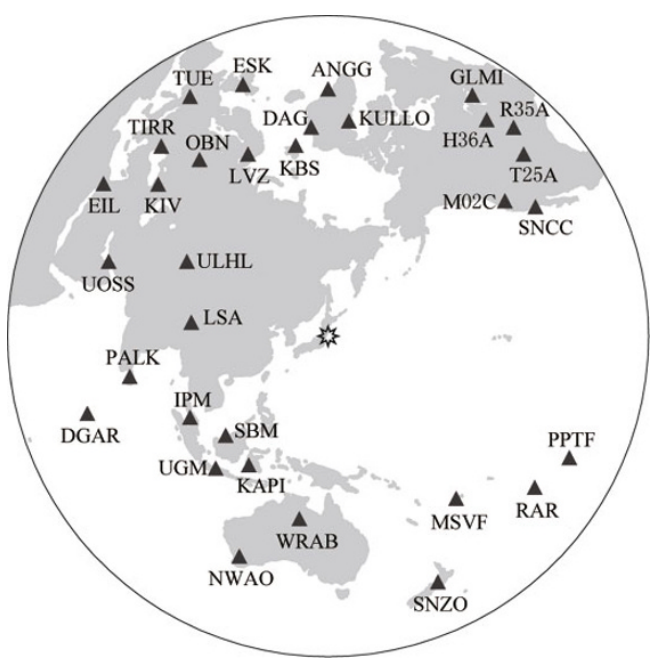

Figure 2 The epicenter (aniseed star) location and distribution of 32 teleseismic stations (triangles). of latitude $35^{\circ} \mathrm{N}-43^{\circ} \mathrm{N}$ and longitude $136^{\circ} \mathrm{E}-142^{\circ} \mathrm{E}$ (Figure 3) and discarded the data outside the abovementioned area due to the low signal-to-noise ratio levels. All three components of GPS data were used and each of them was allocated with equal weights in the inversion. The method of Okada (1985) was taken to calculate the ground surface deformation caused by a unit slip on a rectangular fault.

\section{Inversion}

For a large thrust fault with a shallow dip-angle, such as the Tohoku earthquake, the geometric parameters are hard to be accurately determined by moment tensor inversion because in the teleseismic distances the seismic rays are of almost the same take-off angles, thus 

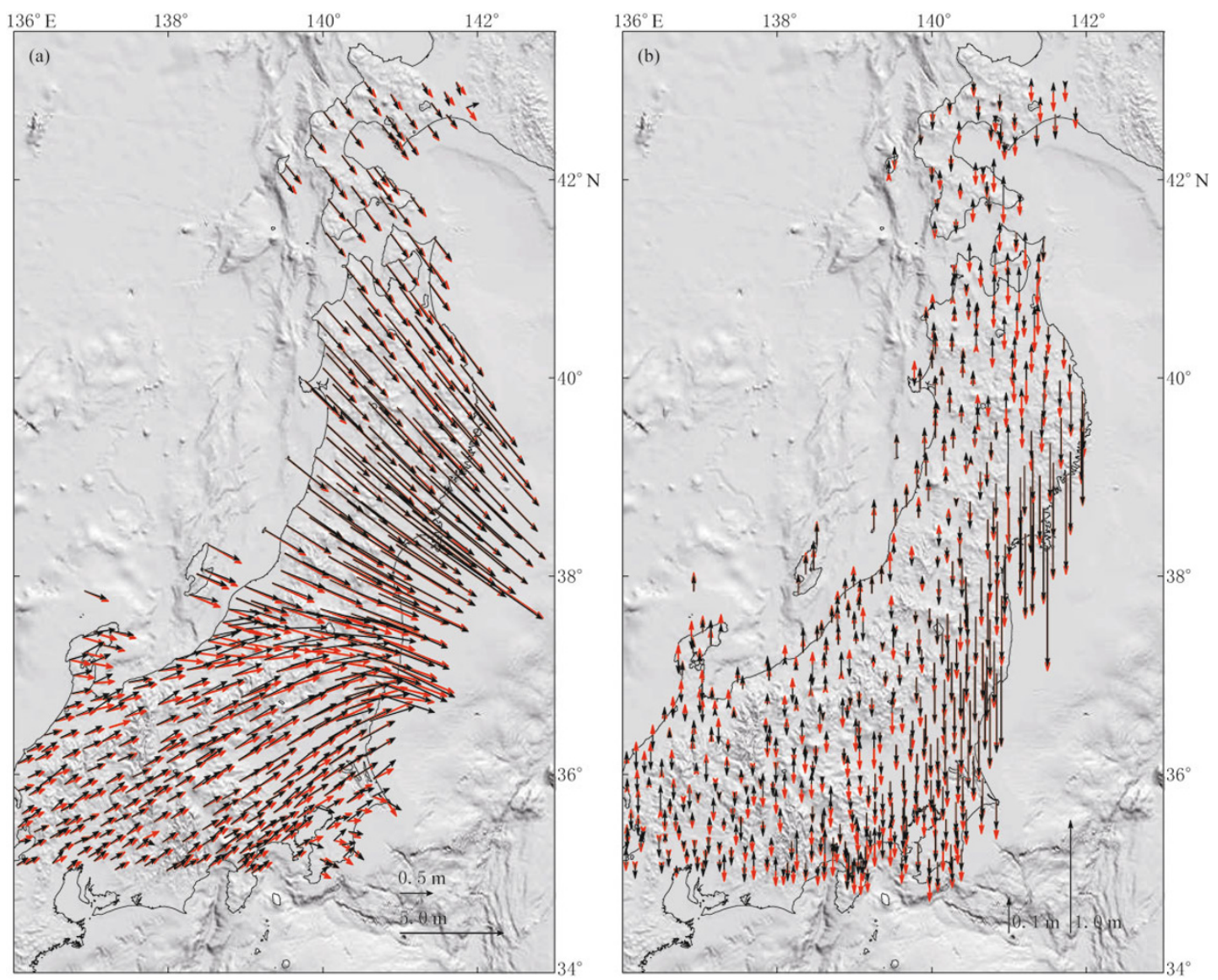

Figure 3 Observed (black arrows) and synthetic (red arrows) GPS measurements in horizontal components (a) and vertical components (b) for the joint inversion.

the strike and dip of the fault are difficult to be resolved. That is why the moment tensor inversion results are quite diverse. However, for the Tohoku earthquake, no near-field geodetic data with good azimuthal coverage on the fault is available for the causative fault determination. Therefore, we checked the focal mechanism results issued by various organizations or authors, and finally adopted the fault plane striking $193^{\circ}$ and dipping $14^{\circ}$ from the USGS $\mathrm{W}$ Phase moment tensor solution to construct the fault model. A $620 \mathrm{~km} \times 240 \mathrm{~km}$ rectangular fault was divided into $31 \times 12=372$ sub-faults with each having the size of $20 \mathrm{~km} \times 20 \mathrm{~km}$. The rupture initiation point (hypocentral location, $38.322^{\circ} \mathrm{N}, 142.369^{\circ} \mathrm{E}$, focal depth $32 \mathrm{~km}$ ) was fixed at the 16th and 7th subfault in strike and dip direction, respectively.

In order to jointly invert the seismic and GPS data, based on the body wave linear inversion technique (Zhang et al., 2009), we transformed the equations of GPS data inversion to make sure the unknown parameters the same as that of seismic data inversion. By giving a relative weight to the GPS data and putting the equations of seismic and GPS data inversions together, we got the equations of the joint inversion. In this joint inversion, only the maximum values of rupture velocity and rupture duration for each sub-fault are assigned beforehand, and the source time functions of the subfaults are obtained automatically as the output of the inversion. In the application to the Tohoku earthquake, the maximum rupture velocity and the maximum rupture duration were assigned to be $3 \mathrm{~km} / \mathrm{s}$ and $60 \mathrm{~s}$ for each sub-fault, respectively.

We first empirically determined the weights of constraints for the seismic data inversion only and GPS data inversion only, respectively. Then by fixing the constraint weight, we searched for the weight of GPS data relative to seismic data. Figure 4 shows the variation reduction (VR) curves (Kim and Dreger, 2008) of the seismic data, GPS data and the average. It is found that 0.4 is the best weight which makes the joint inversion best interpret the seismic data and GPS data simultaneously (Figure 4). The small weight $(<1)$ of the GPS data can be reasonably accounted for the facts that all 

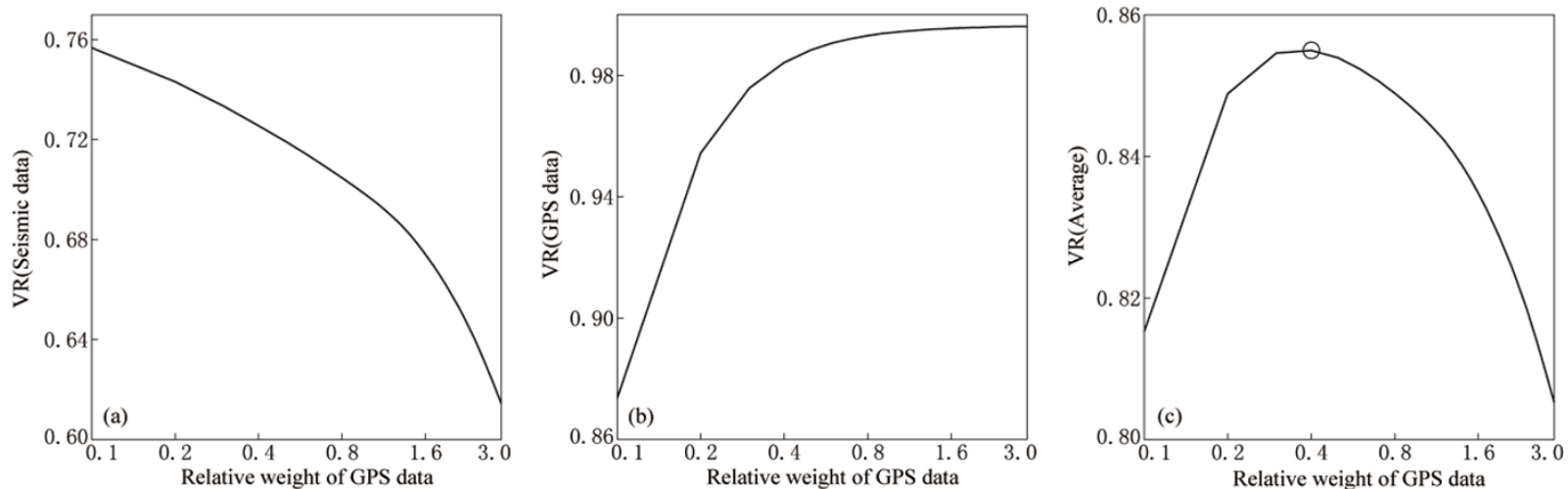

Figure 4 Variation reduction (VR) of seismic data (a), GPS data (b), and the average (c).
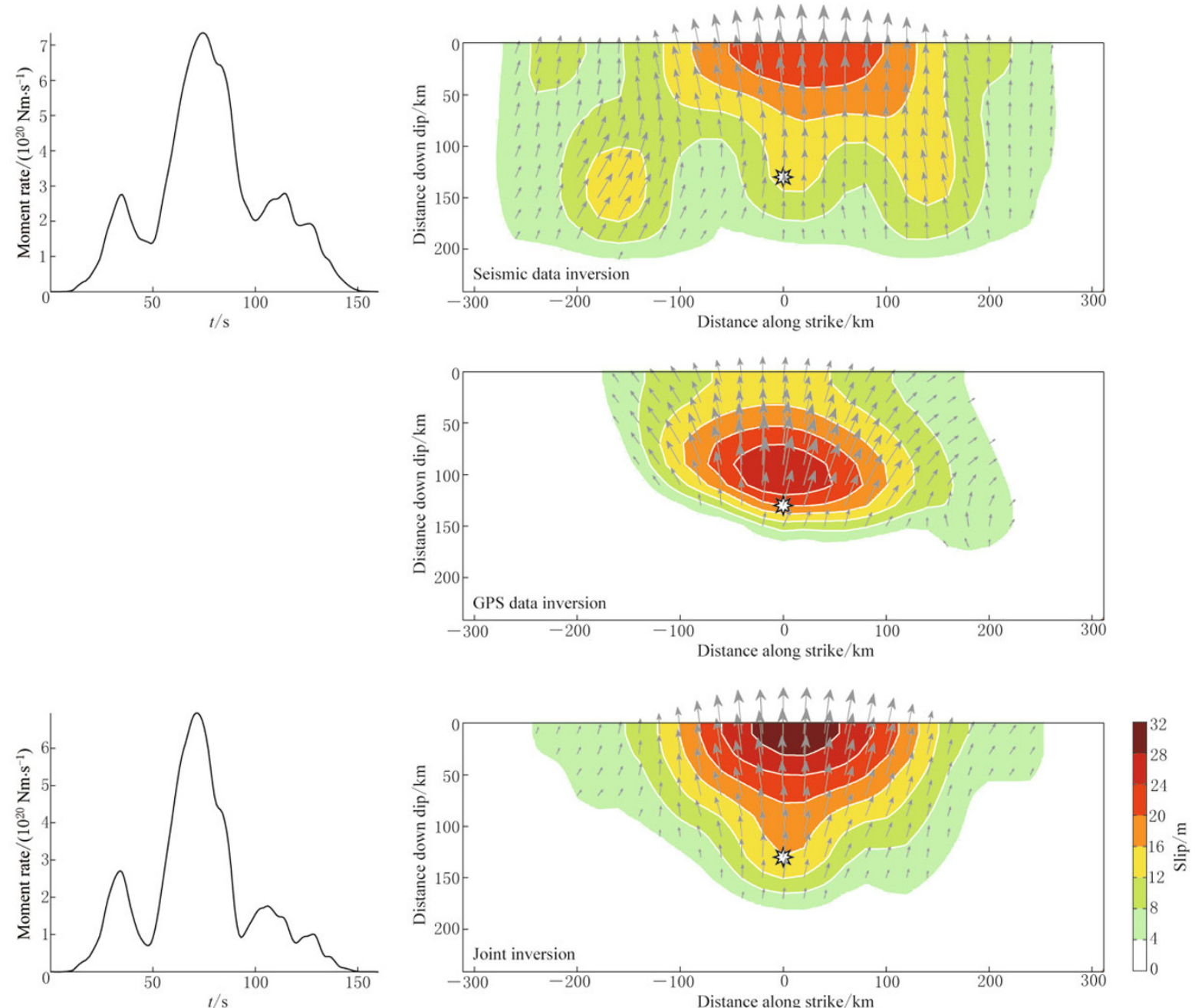

Figure 5 The source time function (left panels) and static (final) slip distribution on the fault plane (right panels) obtained by seismic data inversion (top), GPS data inversion (middle), and the joint inversion (bottom). White aniseed star represents the hypocenter (rupture initiation point) on the fault. 
GPS stations are located to the west of the epicenter and the azimuthal coverage on the fault is poor.

\section{Results}

The scalar moment obtained in seismic data inversion, GPS data inversion and joint inversion are $3.8 \times 10^{22} \mathrm{Nm}, 2.2 \times 10^{22} \mathrm{Nm}$ and $2.9 \times 10^{22} \mathrm{Nm}$, which correspond to moment magnitudes of $M_{\mathrm{W}} 9.0, M_{\mathrm{W}} 8.8$ and $M_{\mathrm{W}} 8.9$, respectively. The static (final) slip distribution shows that the earthquake is a bilateral rupture event, and the size of the ruptured area is about $500 \mathrm{~km}$ long and $180 \mathrm{~km}$ wide. The maximum slip is about 30 $\mathrm{m}$, breaking through the sea bed.

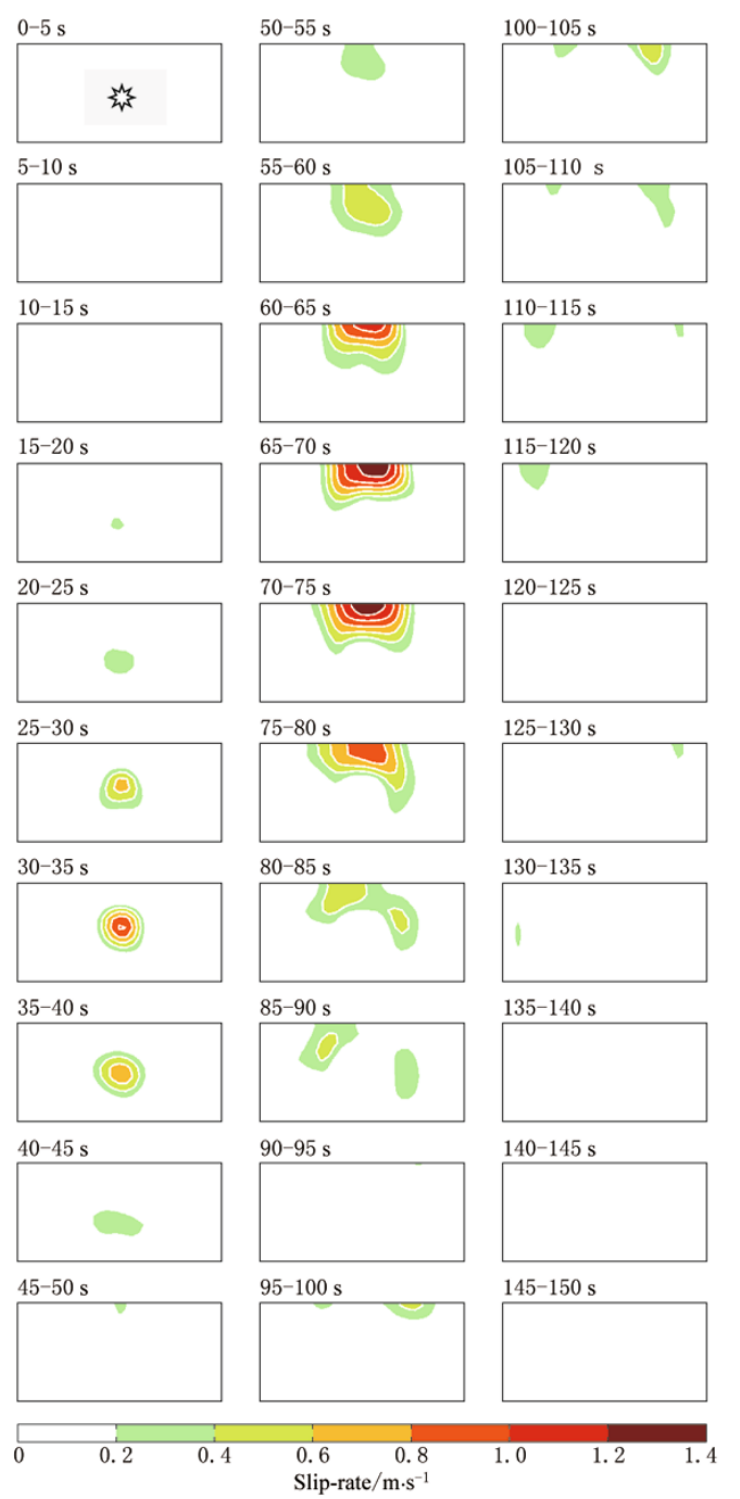

Because the co-seismic deformation of GPS data cannot resolve the temporal source process, the source time function obtained in the joint inversion is similar to that of seismic data inversion (Figure 5). The source duration is about $150 \mathrm{~s}$, consisting of three major sub-events occurred at 0-50 s, 50-90 s and 90-150 s, respectively. The first sub-event ruptured very slowly, especially in the first 10 seconds, with a circular rupture mode around the hypocenter; then the second and the third sub-events both ruptured in a shallower depth and broke through the sea bed (Figure 6). The rupture propagated very slow and the average rupture velocity was estimated to be $1.8-2.0 \mathrm{~km} / \mathrm{s}$, similar to the results of Shao et al. (2011).
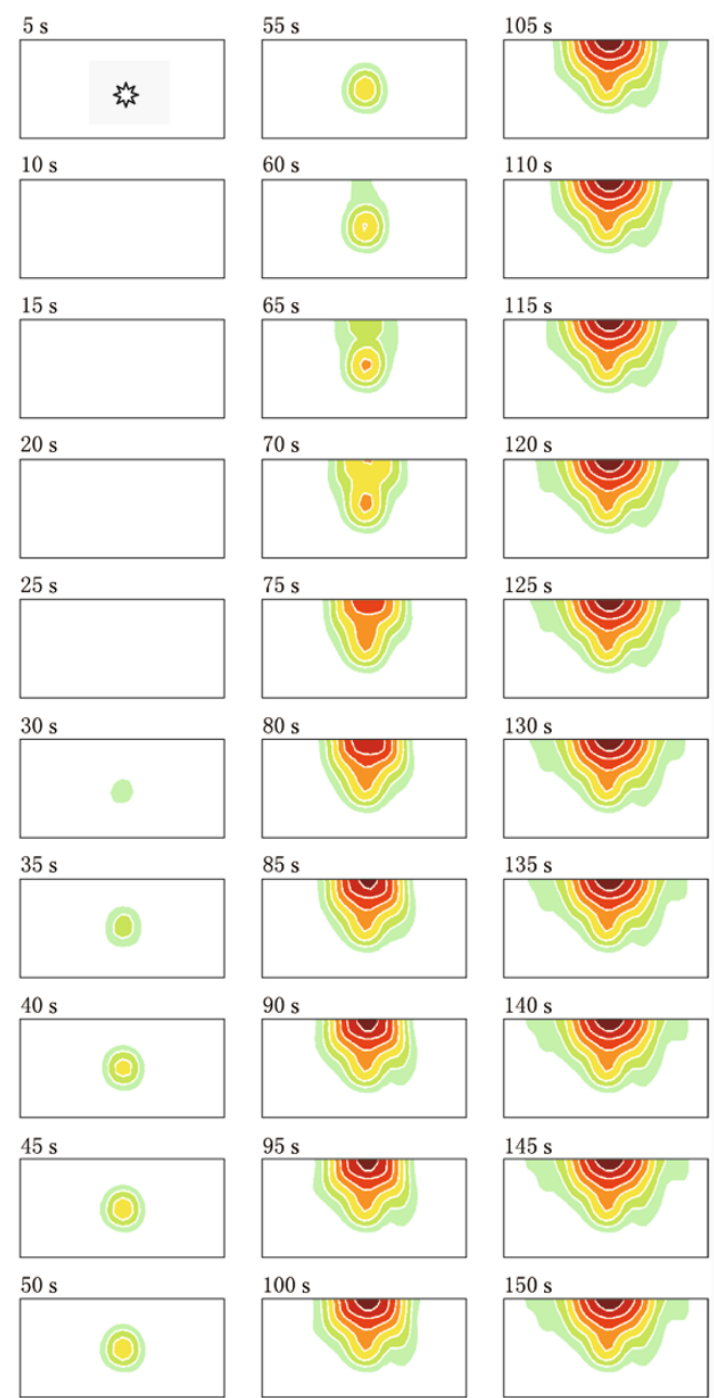

$150 \mathrm{~s}$

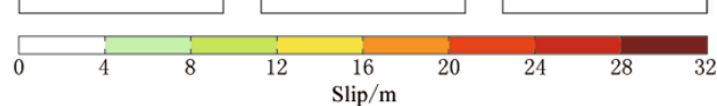

Figure 6 Temporal variation of the slip-rate distribution (left panel) and slip distribution (right panel) on the fault for each $5 \mathrm{~s}$. 


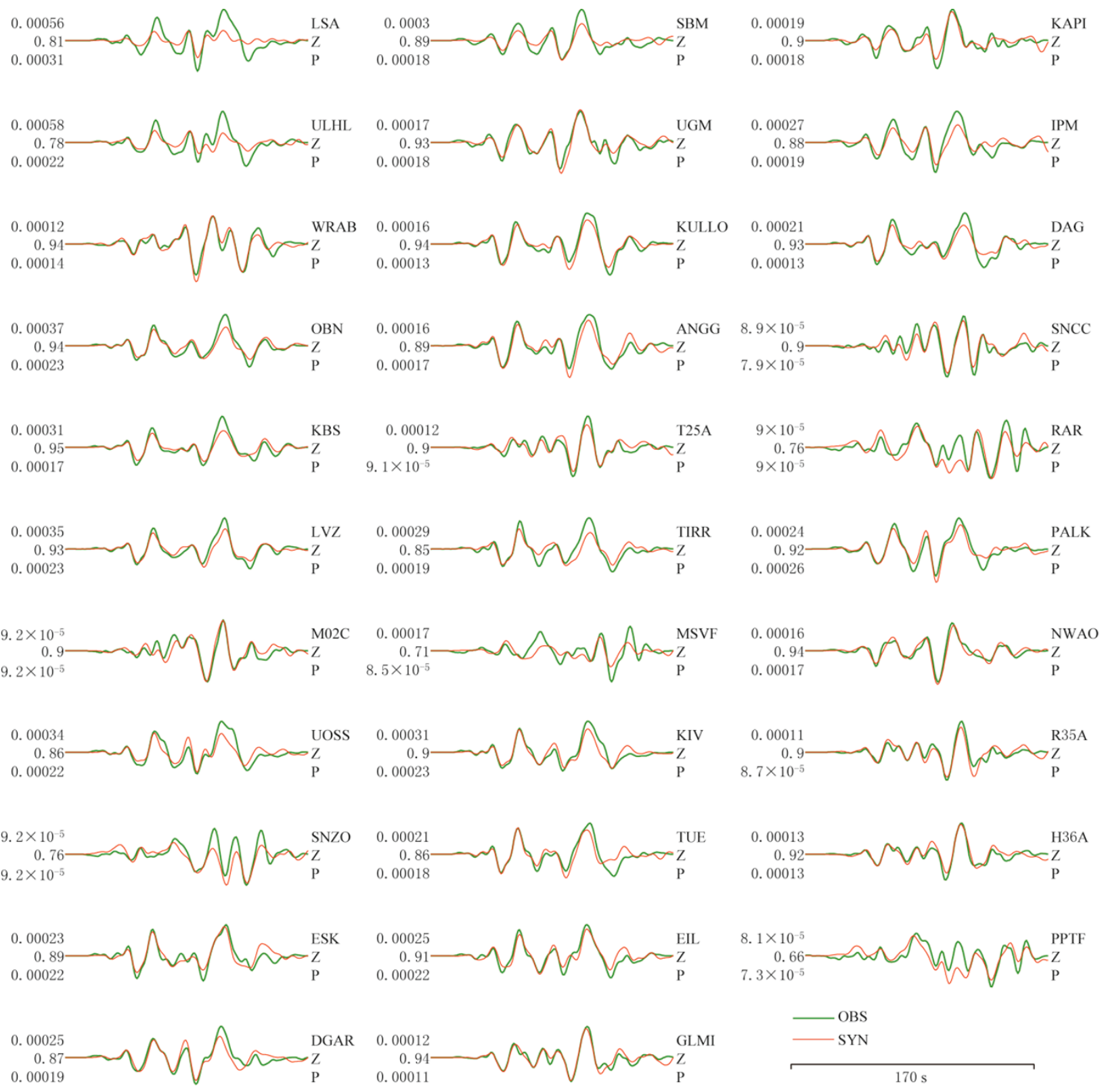

Figure 7 Comparison of observed and synthetic seismic waveforms for the joint inversion. On the left of each sub-graph, from top to bottom are the maximum amplitude (units: $\mathrm{m} / \mathrm{s}$ ) of observed waveforms, the correlation coefficients of the observed and synthetic waveforms, and the maximum amplitude of synthetic waveforms. On the right of each sub-graph, from top to bottom are the station codes, component names and phases of seismic waves.

By using the Brune's model (Brune, 1970, 1971) to each sub-faults, the maximum and average stress drop were calculated based on the inverted static slip distribution. They are about $111 \mathrm{MPa}$ and $46 \mathrm{MPa}$, respectively.

\section{Discussion and conclusions}

Because of the shallow dip angle of thrust fault, the co-seismic deformation of vertical components is much smaller than that of horizontal components, thus their interpretation is not very well (Figure 3b). Besides, although the azimuthal coverage of the GPS data on the fault is incomplete, since all the GPS stations are located on the hanging-wall, it can also partially constrain the rupture extension and slip distribution along the strike direction, and help to obtain a more reliable rupture process result together with the seismic data.

The joint inversion results of seismic and GPS data show that the 2011 mega Tohoku earthquake is a 
bilateral rupture event, which is similar to the study of Yagi and Fukahata (2011) and Hao et al. (2011). The ruptured area with the largest slip amplitude is located near the Japan Trench around the latitude $38^{\circ} \mathrm{N}$ where strong lateral heterogeneities and high velocity areas cause asperities and strong-coupled portions (Zhao et al., 2009; 2011). In the first 10 seconds after earthquake initiation the rupture was very weak. Then the rupture propagated bilaterally with an average rupture velocity less than $2.0 \mathrm{~km} / \mathrm{s}$. It also shows that the Tohoku earthquake rupture had broken through the sea bed which may account for the excitation of the huge tsunami which caused a tremendous casualties and damage.

Acknowledgements This study was financially supported by the National Natural Science Foundation of China (Nos. 90915012 and 41090291), and the Research Project in Earthquake Science, CEA (No. 201108002).

\section{References}

Brune J N (1970). Tectonic stress and the spectra of seismic shear waves from earthquakes. $J$ Geophys Res 75: 4 997-5 009.

Brune J N (1971). Correction. Tectonic stress and the spectra of seismic shear waves from earthquake. $J$ Geophys Res 76: 5002.

Hao J L, Wang W M and Yao Z X (2011). Source process of the $2011 M_{\mathrm{W}} 9.0$ Tohuko Japan earthquake. Science in China (Series D) 54: 1 105-1 109, doi:10.1007/s11430011-4241-y.

Hayes G (2011). Updated Result of the Mar 11, $2011 M_{\mathrm{W}} 9.0$ Earthquake Offshore Honshu, Japan. [2011-03-11] http://earthquake.usgs.gov/earthquakes/eqinthenews/ 2011/usc0001xgp/finite_fault.php.

Heki K, Miyazaki S and Tsuji H (1997). Silent fault slip following an interplate thrust earthquake at the Japan Trench. Nature 386: 595-598.

Kennett B L N (1983). Seismic Wave Propagation in Stratified Media. Cambridge University Press, Cambridge: 1339.

Kennett B L N and Engdahl E R (1991). Travel times for global earthquake location and phase identification. Geophys J Int 105: 429-465.

Kim A and Dreger D S (2008). Rupture process of the 2004 Parkfield earthquake from near-fault seismic waveform and geodetic records. J Geophys Res 113: B07308, doi:10.1029/2007JB005115.

Okada Y (1985). Surface deformation due to shear and tensile faults in a half-space. Bull Seismol Soc Am 75(4): 1 135-1 154.

Seno T, Sakurai T and Stein S (1996). Can the Okhotsk plate be discriminated from the North American plate? $J$ Geophys Res 101: 11 305-11 3156.

Shao G, Li X, Ji C and Maeda T (2011). Focal mechanism and slip history of $2011 M_{\mathrm{W}} 9.1$ off the Pacific coast of Tohoku earthquake, constrained with teleseismic body and surface waves. Earth Planets Space 63(7): 559-564.

Wei S J, Anthony S and ARIA group (2011). Updated Result 3/11/2011 ( $\left.M_{\mathrm{W}} 9.0\right)$, Tohoku-oki, Japan. [2011-03-12] http://tectonics.caltech.edu/slip_history/2011_taiheiyooki/index.html.

Yagi Y (2011). The 11 March 2011 Tohoku earthquake. (in Japanese) [2011-03-12] http://www.geol.tsukuba.ac.jp/ yagi-y/EQ/Tohoku/index-o.html.

Yagi Y and Fukahata Y (2011). Rupture process of the 2011 Tohoku-oki earthquake and absolute elastic strain release. Geophys Res Lett 38: L19307, doi:10.1029/2011GL048701.

Zhang Y, Feng W P, Xu L S, Zhou C H and Chen Y $\mathrm{T}$ (2009). Spatio-temporal rupture process of the 2008 great Wenchuan earthquake. Science in China (Series D) 52(2): 145-154.

Zhang Y, Xu L S and Chen Y T. (2011). Fast rupture process inversion of the 11 March 2011 earthquake near the east coast of Honshu, Japan. [2011-03-11] http://ddsep.ceaigp.ac.cn/rp/2011.

Zhao D, Huang Z, Umino N, Hasegawa A and Kanamori H (2011). Structural heterogeneity in the megathrust zone and mechanism of the 2011 Tohoku-Oki earthquake $\left(M_{\mathrm{W}} 9.0\right)$. Geophys Res Lett 38: L17308, doi:10.1029/2011GL048408.

Zhao D, Wang Z, Unimo N and Hasegawa A (2009). Mapping the mantle wedge and interplate thrust zone of the northeast Japan arc. Tectonophysics 467: 89-106. 